\title{
Penélope. La tejedora de artimañas
}

\author{
Penelope. The tricker weaver
}

\author{
MARIa VANeSA MaRiño CALVo \\ Universidad de Santiago de Compostela \\ ORCID: 0000-0001-6772-8467
}

Recibido: 08/6/2020

Aceptado: $13 / 1 / 2021$

doi: https://doi.org/10.20318/femeris.2021.6403

Resumen. En la antigua Grecia la palabra pertenecía al varón. Las mujeres vivían relegadas en un segundo plano y sus mayores cualidades eran el recato, la modestia, la fidelidad, mantenerse en silencio y la laboriosidad. Precisamente, es, en el trabajo, donde el imaginario griego, plasmado en el mito, concede una voz a la mujer a través del objeto y la actividad que mejor la identifica: el telar y el tejido.

El telar es el instrumento que rige el mundo femenino. Ya, desde la más tierna infancia, las niñas son instruidas en el manejo y el dominio de la tejeduría; un arte que se convertirá en metáfora de la unión sexual plena que dará como fruto hijos legítimos, pero, también, se transformará en el medio de comunicación de las mujeres. Muchos son los ejemplos de féminas que consiguen hacerse ver y oír a través del diseño de sus tejidos -Filomela, Quelidón, Helena, Aracne, etc.-; no obstante, el mayor referente en este campo se nos presenta en la lírica homérica: Penélope.

Al igual que otras féminas, Penélope sólo puede pronunciarse mediante su trabajo en el telar. Sin embargo, y a diferencia de las demás, la esposa de Odiseo ha sido bendecida con el don de la mêtis: la inteligencia o la astucia que le permite engañar a los pretendientes mediante la maniobra de tejer y destejer el manto fúnebre de Laertes.

En este contexto, tejer se traduciría como el decir -la promesa de la elección de un pretendiente-, mientras que destejer sería interpretado como el desdecir una demostración de fidelidad hacia su esposo y un acto de protección, tanto de la memoria del héroe como de su riqueza.

Palabras clave: mujer, telar, tejer, mêtis, Penélope.

Abstract. In ancient Greece the word belonged to the male. Women lived relegated in the background and their greatest qualities were modesty, fidelity, silent, and industriousness. It is precisely in this field of work where the Greek imaginary, embodied in the myth, grants a voice to women through the object and activity that best identifies them: the loom and the fabric.

\footnotetext{
*El presente artículo se encuadra dentro del proyecto de investigación "Los lugares del saber en la Atenas democrática (TOPOSOFÍA)" financiado por el Ministerio de Ciencia e Innovación del Gobierno de España (PID2019-106782GB-I00) y el "Programa Logos Fundación BBVA de Ayudas a la Investigación en el Área de Estudios Clásicos" - Fundación BBVA y Sociedad Española de Estudios Clásicos.
} 
The loom is the instrument that governs the feminine world. Already, from the earliest childhood, girls are educated in the management and mastery of weave; an art that will become a metaphor for full sexual union that will result in legitimate children, but will also become the means of communication for women. Many are the examples of females that manage to make themselves seen and heard through the design of their fabrics -Filomela, Quelidon, Helen, Arachne, etc.-; however, the greatest reference in this field is presented to us in Homeric's lyric: Penelope.

Like other females, Penelope can only pronounce by working on the loom. However, unlike the others, Odysseus' wife has been blessed with the gift of metis: intelligence or cunning that allows him to deceive suitors by maneuvering to weave and to unpick Laertes' funeral mantle.

In this context, weaving would translate as saying -the promise of the choice of a suitor-, while unpicking would be interpreted as not to say - a demonstration of fidelity to her husband and an act of protection, both from the memory of the hero and of his wealth.

Keywords: woman, loom, weave, mêtis, Penelope.

En la antigua Grecia, la palabra pertenecía a los varones: solo ellos tenían acceso a expresarse públicamente, ya fuese en el ágora, la asamblea o los tribunales ${ }^{1}$. Las mujeres, por norma general, vivían relegadas en un segundo plano y sus mayores cualidades eran el recato, la modestia, la fidelidad, la laboriosidad (Blundell, 1995: 141) y la exigencia de mantenerse en silencio: La virtud de las mujeres reside, por lo que se refiere al cuerpo, en la belleza y el porte, y, por lo que se refiere al alma, en la moderación y en que sean hacendosas sin mezquindad (Arist. Rh. II. 1361 a) ${ }^{2}$.

Desde el instante mismo en que contraían matrimonio, las mujeres -vistas como una propiedad- estaban constreñidas a vivir recluidas en el ámbito del hogar y, dentro de éste, en las estancias del gineceo; espacio donde desempeñaban aquellas labores que, además de serle propias (Gea Izquierdo, 2013: 184 ss.), moldeaban su carácter convirtiéndolas en el prototipo de mujer que todo griego desearía para sí mismo.

El deber para con la maternidad junto con la realización de las labores de índole textil, el mandato y la administración del oikos, impedían que las féminas pudiesen salir de sus hogares de forma habitual, un hecho que podría relacionarse con la descripción de la mujer-abeja aportada por Semónides de Amorgos en su obra Sobre las mujeres (Fr. 7). Entre las muchas aptitudes dignas de alabanza que, a ojos del poeta, presenta este ejemplo de fémina, se resalta su gran discreción al evitar juntarse con sus congéneres con el fin de mantener conversaciones banales sobre cuestiones amorosas o sexuales (Lefkowitz, 1983: 32-33). Se impedía así, una reiterada ausencia del hogar con el abandono de los quehaceres o el incurrir en una infidelidad que pudiese exponer, públicamente, al esposo y a la familia dañando su reputación.

Es aquí donde, a las mujeres, además de sometérselas a una vigilancia y control permanentes, se les niega la voz y, también, la opinión: Mas ve a casa y ocúpate de tus labores, el telar y la rueca, y ordena a las sirvientas aplicarse a la faena. Del combate se cuidarán los hombres todos que en Ilio han nacido y yo, sobre todo (Hom. Il. VI. 490-493).

\footnotetext{
${ }^{1}$ Véase la caricaturesca imagen que propone Aristófanes en Las Asambleístas o Lisístrata, así como Bruit Zaidman (1992: 373); hecho que reafirma Blok (2017: 173).

${ }^{2}$ Estas características mostraban el paradigma de mujer "ideal"; no obstante, en ocasiones, algunos autores como Plutarco (Moralia 3.4), relatan con gran admiración la hazaña de la joven poetisa Telesila que, ante la invasión de los espartanos, llamó a armas a todas sus congéneres; consiguiendo así, rechazar el ataque.
} 
Sin embargo, muchas mujeres griegas sí poseen inteligencia y entendimiento, aunque solo puedan hablar en situaciones de emergencia o peligro e, incluso, en tales ocasiones, el modelo a imitar es el masculino (Lefkowitz, 1986: 86). Tal afirmación puede verse ejemplarizada en la comedia de Aristófanes, Lisístrata ${ }^{3}$, cuando la heroína relata cómo todo su saber es fruto de los discursos que, de boca de su padre y otros varones adultos de la comunidad, ha escuchado; acción que la muchacha, con toda probabilidad, ha debido llevar a cabo desde el silencio y una posición de máxima discreción.

Aristóteles, en su Política (VII. 16, 1335 a), exponía que las mujeres debían contraer matrimonio hacia los dieciocho años mientras los varones lo realizarían próximos los treinta y siete. La diferencia de edad entre los cónyuges producía tal disimetría estructural que el esposo acababa por convertirse en el maestro de la joven (Andò, 2005); de esta forma, las mujeres estaban abiertas a la recepción de las enseñanzas de sus maridos sobre cómo convertirse en una buena esposa -el arte de la seducción era totalmente inservible por resultar dañino y engañoso (X. Oec. X. 1-9)-, previniendo transformase en objeto de burla o que el esposo acabase consumido por los excesivos apetitos de la mala mujer.

Mediante este aprendizaje, los hombres no solo moldeaban el carácter femenino en pos de un ser dócil y solícito, también conseguían imprimirle una serie de valores que, con el paso del tiempo, la volviesen una devota de la vida en el interior de la vivienda. De este modo, el espacio exterior podría seguir perteneciendo a los varones como el lugar de intercambio de ideas (Iriarte, 1990: 130).

Pese a la concepción que, a nuestros días, ha llegado sobre la opresión de las mujeres y la negación de la palabra femenina a manos de la cultura griega, podríamos llegar a afirmar que, en verdad, sí existía un tipo de saber y un modo de expresión atribuidos a las féminas cuyo desarrollo, de forma habitual, fue llevado a cabo en el espacio del gineceo, mientras era regido por el ritmo del telar (...) (Iriarte, 1990: 130).

Hasta hace unos años, el estudio de la producción textil en la Grecia antigua había sido, para el mundo de la investigación, un tema desatendido, incluso sabiéndose que constituía una parte trascendental para el entendimiento de la vida social y cultural del pasado (Nosch, 2014: 91). En un gran número de civilizaciones, entre ellas la griega, el arte de la tejeduría solía relacionarse con las narraciones mitológicas o la cosmología. Simbólicamente, dicha labor vendría a describirse como el acto poético de una actividad creadora (Assaël, 2002: 145 s.), algo que podría ser ejemplarizado en la figura legendaria de las Moiras: las diosas hilanderas o tejedoras encargadas de trazar la urdimbre de la existencia y el destino del ser humano. Igualmente, estas labores estarían en estrecha relación con la vida sexual y la función procreadora de las mujeres terrenales; quienes, además, emplearían este conocimiento y domino del telar como método para la construcción del discurso femenino griego.

Este trabajo, al ser una muestra del poder que poseen las mujeres, se vio abocado a la invisibilidad y a ser realizado en un ámbito de reclusión por no tener el reconocimien-

\footnotetext{
${ }^{3}$ Por mí misma no ando mal de inteligencia y además he oído hablar muchas veces a mi padre y a las personas de edad, así que mi instrucción es buena (Ar. Lys., 1126-1129).
} 
to de los varones (Fernández Guerrero, 2012: 113); cuestión bastante contradictoria si tenemos en cuenta que la destreza en el hilado y el tejido estaban entre las aptitudes femeninas más aplaudidas entre padres y esposos. Por ello, no sorprende hallarse, tanto en las fuentes clásicas -con distinción de la tragedia, la comedia y las epopeyas homéricascomo en la mitología, a un amplio número de féminas dedicadas al desempeño de estas funciones. Sin embargo, de entre todas estas heroínas, sería necesario subrayar aquellas que presentan una mayor relación con el telar y su aplicación como el instrumento que les otorgaría una voz propia: Aracne, Procne y Filomela y la singular Penélope.

\section{Aracne}

Cuenta el relato del latino Ovidio (Met. IV. 1-145) que en la tierra de Lidia habitaba una muchacha, Aracne, capaz de igualar a la mismísima Atenea en el manejo de la lana y los útiles propios de la tejeduría y el hilado. Esta habilidad, adquirida sin la ayuda o enseñanza de nadie -al ser huérfana de madre, e ignorar y rechazar Aracne la tutela de una mujer (Frontisi-Ducroux, 2006: 256)-, la hizo ganarse tal fama y renombre que gentes llegadas desde lejanas tierras venían a contemplar su obra y verla trabajar. Su gran destreza a la hora de manejar los hilos provocaba que se le atribuyese el mérito de su labor a la instrucción de Atenea, hecho que la joven no aprobaba. Por ello, en un ataque de vanidad, reta a la propia Atenea a una competición para ver quién era la mejor tejedora.

La diosa, habiendo adoptado la forma de una anciana, advierte a la joven sobre su descaro y atrevimiento; sabias palabras que Aracne ignora. Atenea se quita el disfraz y da comienzo el concurso. Mientras la Tritonia borda escenas que muestran el poder y el esplendor de los doce dioses celestiales, la Meónide plasma las metamorfosis adoptadas por las divinidades masculinas, Zeus el primero, con el fin de seducir a los mortales.

El desafío a la divinidad, así como otro tipo de ofensas, conlleva un castigo y, Aracne, en ese exceso de orgullo que no soportan los dioses (Frontisi-Ducroux, 2006: 252), incurre en delito. Esta insolente acusación hacia los dioses al narrar aquello que no debe ser contado, junto con la perfección y belleza del bordado de la joven, provocan que Atenea destruya la tela de Aracne; quien, al no poder soportar su desventura, acaba suicidándose, muerte trágica, quizá, que eligen abrumados por la desazón, aquellos sobre quienes recae el dolor excesivo de un infortunio irremediable (Loraux, 1989: 33).

La diosa, compadecida ante la situación, mitiga el destino de la muchacha trocándola en araña; transformación que, a partir de las palabras que Atenea expresa ${ }^{4}$, podría interpretarse como un toque de atención a todas aquellas jóvenes que pecan de arrogancia, prefiriendo centrarse en sí mismas y sus placeres que en esforzarse por convertirse en esposas fieles, madres ejemplares y provechosas administradoras del hogar mediante el correcto empleo de las actividades femeninas. Tales tareas, al vincularse con el oficio de

\footnotetext{
${ }^{4}$ ¡Mantente viva aún, pero cuelga, desvergonzada, y que este mismo tipo de castigo, para que no estés libre de preocupación por el futuro, sea dictado para tu linaje y tus lejanos descendientes! (Ov., Met., VI, 135 ss.)
} 
la hilandera y la tejedora, manifiestan una estrecha conexión con la metamorfosis sufrida por Aracne.

Como la más común dentro del orden de los Arachnida, la araña suele caracterizarse por su gran producción de seda; elemento utilizado en la confección de telarañas. De igual forma, en este arácnido, por la particular naturaleza de su físico, podrían escudriñarse rasgos análogos a los presentes en el carácter de cualquier fémina: así como la araña es incapaz de comunicarse vía oral o emitir algún tipo de sonido, las mujeres griegas se distinguen por saber guardar silenci, algo de lo que Aracne, por la arrogancia de su juventud, se cree eximida. También, por ser la araña un ser engañoso -trabaja afanosamente en tejer una tela, casi imperceptible a la vista, que luego empleará para atrapar a sus víctimas durante la caza (Plu., Moralia 9. 966 F)-, se la asocia con relación al carácter dual de las féminas que tanto pueden ser fieles e irreprochables, como instigadoras de las mayores tramas y ardides (Gualerzi, 2007: 145).

Aunque sea una magnífica tejedora, la joven lidia carece de la corrección y la educación que transmite una madre; hecho que la priva de las cosas que toda muchacha debe conocer: la modestia, la reserva, la discreción y que las cuestiones de índole sexual son secretos que deben mantenerse guardados, sobre todo si estos atañen a los dioses (FrontisiDucroux, 2006: 256).

Esta falta de conocimiento del mundo femenino, unida a una enseñanza predominantemente paterna, suscitan que Aracne actúe como un varón negando la esencia propia de las féminas. A esto es preciso añadirle que, al proclamarse como autodidacta en su oficio, también está rechazando la transmisión cultural y religiosa que une a la diosa con las mujeres a las que enseña las labores femeninas (Frontisi-Ducroux, 2006: 256) del hilado y la tejeduría; menesteres de gran importancia pues, en determinados contextos o situaciones, solían utilizarse para crear y dar forma al discurso femenino, actividad en la que Aracne carece de mesura.

Pese a que la cólera de Atenea esté justificada, cierto es que la mutación de Aracne, si aplicamos los parámetros sociales griegos, podría interpretarse como un hecho realmente trágico. Para las mujeres, el matrimonio y la maternidad eran los objetivos que daban sentido a la vida (Fantham [et al.], 1995: 5-207); por eso, cuando una joven fallecía en la plenitud de su existencia, sin haber alcanzado tales metas, ya nunca lograría realizarse como fémina. Por consiguiente, a la conversión de Aracne en insecto podría atribuírsele esta lectura, reforzada con el añadido de que la joven, después del maltrato de la diosa, decide quitarse la vida ahorcándose.

Desde el punto de vista de Nicole Loraux (1989: 33-34), esta forma de suicidio es considerada como la muerte propia de las mujeres puesto que, en el ahorcamiento, la expresión de la feminidad se incrementa al sustituirse la soga por los tejidos o adornos -lazos, velos, etc.- que las féminas emplean para cubrirse. Personalmente, me atrevería a conjeturar que tal forma de violencia podría entenderse como metáfora de la situación femenina en la Grecia Antigua. Las mujeres, al hacer uso de sus propias prendas para colgarse, estarían alterando el significado y el propósito primordial que la labor de la tejeduría divulgaba. Así, en el contexto del matrimonio y el hogar, esta actividad se interpretaría 
como la unión sexual entre ambos cónyuges (Frontisi-Ducroux; Vernant, 1997); acto equiparable al entrelazamiento realizado con el hilo de la trama y el de la urdimbre (Assaël, 2002: 146). Además, dicho enlace daría lugar al nacimiento de hijos legítimos: el objetivo máximo que, por su sexo, les otorgaba la sociedad.

Por otra parte, al efectuarse el estrangulamiento de la tráquea se estaría infringiendo un gran daño en las cuerdas vocales, originando, como consecuencia, una pérdida del habla. Con esto, las mujeres se estarían sometiendo, a sí mismas, a un proceso de silenciamiento y privación de la voz y la palabra; hecho que acrecienta, aun más, el poder y el control masculino.

\section{Filomela y Procne}

Si, en la historia de Aracne, el expresarse a través de la tejeduría y su instrumento se convierte en motivo de castigo, en el mito de Procne y Filomela, esta labor sirve como resolución de un conflicto: la mujer, incapacitada para hablar, solo puede relatar el suceso de su desgracia a través del fruto de su trabajo en el telar.

Este episodio (Ov. Met. VI. 424-674), tratado por numerosos autores y objeto de múltiples variantes -existe un relato anterior de similares características que desarrolla las penurias de Aedón y Quelidón-, narra cómo Pandión, soberano ateniense, entrega en matrimonio -pese a lo poco halagüeño que eran los presagios- a su hija mayor Procne.

Desposada con Tereo, rey de los tracios, pronto se convierte en madre del pequeño Itis. Pero la dicha no es completa, pues, con la nostalgia de quien ha abandonado el hogar, Procne vive con la añoranza de ver a su queridísima hermana Filomela. Cumpliendo los anhelos de su esposa, Tereo viaja en busca de la muchacha; no obstante, cuando llega a Atenas y contempla a la hermosa doncella, su deseo se enciende llevándole a cometer un horrible delito: viola a la joven, atentando contra su estado de parthenos -se produce una relación sexual no consentida, cuyo fin es la obtención de placer y no la procreación de hijos legítimos (Frontisi-Ducroux, 2009: 118 ss.)- y, acto seguido, le corta la lengua para impedir que revele lo sucedido.

A partir de ese instante, Filomela -a quien Procne da por muerta- se convierte en cautiva de Tereo. Llegados a este punto, cabría mencionar la existencia de una inteligencia o prudencia astuta -propia del hombre excepcional e innata a todas las mujeres-, que habla de la eficacia práctica y del saber útil, así como de las artimañas o tretas (Detienne; Vernant, 1988: 17-18). Esta capacidad forma parte de la naturaleza femenina desde la creación de Pandora, a quien Atenea le confirió el arte, la praxis y la astucia que definen los trabajos manuales -de Pandora, además de descender todas las féminas, surge la tradición de trabajar la lana y amar esa tarea tan servil (Frontisi-Ducroux, 2009)-; siendo la tejeduría una ocupación exclusivamente femenina, por ser las mujeres las únicas aptas para llevarla a cabo (Iriarte, 1990: 31 ss.).

Filomela es capaz de mostrar una gran mêtis, lo cual, pese a su incapacidad para expresarse oralmente, le permite idear una estratagema para dar testimonio del crimen al 
que ha sido sometida: mediante el empleo del telar, confecciona un tapiz en el que plasma lo acaecido y se lo hace llegar a Procne. La silenciosa palabra de la joven resulta peligrosa desde el momento en que su tejido sobrepasa la función de elemento delator de la trasgresión a la que ha sido sometida, y adquiere un cariz mistérico al relacionarse con el mundo de la sexualidad y los secretos propios de la comunidad femenina a los que los hombres nunca deberían tener acceso (Frontisi-Ducroux, 2006: 241).

Conocedora de la deshonra sufrida por su hermana, Procne, antes de huir con Filomela, trama una terrible venganza: asesinar a su hijo Itis y, posteriormente, servírselo a Tereo como alimento; así, del mismo modo que Medea, la mujer estaría matando indirectamente a su esposo por intermedio de su vástago (Loraux, 89:32). Además, según González González (2008: 23), esta represalia, al tratarse de un suceso predeterminado que conlleva un terrible artificio, podría percibirse como indicativo de que Procne, a pesar de que en el texto se haga mención del carácter astuto de Filomela y Tereo, sería la única poseedora de mêtis dentro la historia. En base a esto, me arriesgaría a matizar esta afirmación: a juicio personal, Procne solo podría ser calificada como única portadora de astucia siempre que esta habilidad se interpretase como un aspecto negativo de la mujer, desde el momento que se presenta en contradicción con la naturaleza femenina al atentar contra su propia descendencia.

Con este mito se hace innegable que las mujeres dominan el arte del engaño; capacidad manifestada a través de la palabra que, a diferencia de la masculina, se conforma con artificios. Esto se convierte en un peligro del que los hombres deben huir -todo en la naturaleza femenina está conformado para atraer al varón-; motivo por el cual, además de silenciada, la palabra de las mujeres es siempre ignorada (Iriarte, 1990).

El patriarcado, atemorizado, lucha por acallar a estas féminas -su mayor miedo es que las mujeres se conviertan en sus interlocutoras; hecho por el cual la Esfinge, experta en idear acertijos y dialogar con el varón, sería tan temida: su palabra es trampa y peligro al mismo tiempo (Iriarte, 1990: 14)-, por ello, se las recluye en las estancias del gineceo: un espacio plenamente femenino al que los varones adultos raramente acceden. Al ser este un lugar perteneciente a las mujeres, los objetos útiles que allí se hallan se ven dotados de un gran valor simbólico; ocultar, cerrar, ordenar, tesaurizar: todos estos actos son propios, (...), de la actividad femenina cotidiana y esencialmente de las mujeres (Lissarrague, 2003: 181). Y, entre estos elementos, despunta, como ya se ha mencionado anteriormente, el telar: instrumento que, junto con el tejido, dota de una "voz" propia a las mujeres. Se conjuga así, un paralelismo entre la palabra enigmática y el entramado de una tela.

\section{Penélope}

A lo largo de la obra homérica, el estudio de la producción textil y temas afines siempre ha sido tratado desde un punto de vista secundario cuando la realidad nos presenta una temática fundamental en la compresión de la sociedad y la narrativa épica reflejadas en la Ilíada y la Odisea (Nosch, 2014: 92). Mientras la Ilíada ofrece una estrecha relación con el mundo masculino por la exhibición de una trama versada en la descripción de ba- 
tallas o contiendas cuerpo a cuerpo, la Odisea, por ser una muestra de la vida cotidiana con los objetos de uso doméstico que la conforman -sábanas, tapices, telas, etc.-, podría fijar un vínculo con el universo femenino (Dalton Palomo, 1996: 53 ss.). Ante esto, no es de extrañar que la Odisea sea el texto que nos presente al paradigma de fémina más alabado por el mundo griego: Penélope.

Penélope es el arquetipo de la feminidad griega. La esposa de Odiseo y reina de Ítaca se revela como la imagen del amor, la belleza y la fidelidad; rasgo, este último, que la distingue, entre todas las figuras femeninas que conforman la mitología de la epopeya -junto con Helena y Clitemnestra-, por ser la única en profesarle un apego, casi excesivo, al esposo ausente (Papadopolou-Belmehdi, 1994: 44). A partir de estas características, se configura un personaje que destacará por ser el paradigma de esposa devota, madre abnegada y sobresaliente tejedora, aptitud que representa la inventiva y la astucia.

Al igual que la misma Pandora -de quien desciende la raza de las mujeres-, la esposa del rey de Ítaca ha sido bendecida, de manos de Atenea, con el don de la mêtis; cualidad que, en su persona, adquiere un valor positivo -al contrario de lo que sucedía con Procnepor su similitud con la inteligencia astuta del propio Odiseo. Dentro del universo femenino homérico, Penélope es el único personaje apto para difuminar los límites entre lo metafórico y lo literal, llevando a confluir, en una misma acción, mêtis y tejido (PapadopolouBelmehdi, 1994: 84).

Con respecto a otras féminas, Penélope se halla en una situación personal privilegiada puesto que, ante la larga marcha de Odiseo, ninguno de los miembros varones de su familia se encuentra en posición de ordenarle o disponerle su voluntad: Laertes por ser demasiado viejo, Telémaco por su juventud y su propio padre por la distancia. Por ello, se ha visto capacitada para mantener su rol de reina y esposa, al mismo tiempo que adopta el papel de parthènos frente a la legión de pretendientes que invade su hogar (Gualerzi, 2007: 31 ss.).

No obstante, al igual que a sus congéneres -la mutilación perpetrada por Tereo a Filomela sería un caso extraordinario, pero podría leerse como la reiteración de la inexistencia de voz que, en el mundo griego, tenían las mujeres-, a esta fémina le será negada la voz: (...) mas tú vete a tus salas de nuevo y atiende a tus propias labores (...) el hablar les compete a los hombres y entre todos a mí (...) (Hom. Od. I. 355 ss.); el tiempo se ha hecho patente y Telémaco, el hijo habido con Odiseo, es ya un adulto. Pero, a diferencia de las demás, su astucia -empleada para mantenerse leal a su esposo, así como para defender su recuerdoes enaltecida; (...) es tu madre más bien, la mujer sin igual en astucias (...) (Hom. Od. II. 88).

La organización del espacio en el mundo griego se estructura de acuerdo con la diferencia entre los sexos: las mujeres, dedicadas al telar, viven excluidas del espacio externo y público donde los hombres, entre otros asuntos, afrontan el riesgo de la muerte gloriosa en la batalla. Así, ante esta disparidad, se construye un tipo de saber femenino ideado en torno al huso y el telar; aunque estos objetos también podrían ser interpretados como emblemas de un destino de exclusión (Andò, 2005: 28-29), al negársele a las mujeres el acceso al ámbito masculino o al rechazarlas cuando irrumpen en el mismo. Por este motivo, Penélope, pese a gozar de una posición aventajada, se ve obligada a confeccionar un engaño con el fin de salvaguardar su estatus como gynè de Odiseo. 
Después de la partida de Odiseo hacia Troya, los pretendientes, codiciosos de la esposa y las riquezas del héroe, irrumpen en el palacio. Allí, luego de asentarse, comienzan a llevar una vida lujosa y plagada de excesos con la que, paulatinamente, van consumiendo la hacienda y dilapidando la fortuna; obligando, además, a que Penélope contraiga nuevas nupcias con uno de ellos. La larga ausencia de Odiseo ha creado un vacío de poder en Ítaca que, ni Laertes ni Telémaco pueden asumir; el uno porque ya ha sido sucedido por Odiseo -hecho por el cual no desempeña un rol político ni goza de influencia-y el otro porque, ante el desconocimiento de si su padre ha fallecido o sigue con vida, no puede alcanzar la posición que le sería propia. Por este motivo, los pretendientes, viendo a Penélope como un medio para alcanzar el poder y la influencia política de Ítaca, la instigan a tomar marido (Osborne, 1996: 143).

Esperanzada con el retorno de un marido a quien no cree muerto, Penélope, que como mujer no está capacitada para encararse con los pretendientes, idea una artimaña que le permita proteger su castidad: solo elegirá esposo cuando finalice un manto fúnebre para su suegro Laertes. Mediante el continuo tejer y destejer de la prenda (Scheid \& Svenbro, 1996: 68) -esta acción podría compararse con el andar del cangrejo, cuyo movimiento oscilante de adelante hacia atrás, recuerda al eterno hacer y deshacer de la fémina (Detienne \& Vernant, 1988: 269 s.)-, la mujer -imagen de la inteligencia femenina: astuta, sutil y, a veces, engañosa (Gera, 1997: 20)- logra embaucar a los pretendientes durante un largo período de tiempo.

La red, vista como un entramado invisible de ligaduras, se convierte en el arma preferida de todos aquellos que han sido agraciados con el don de la astucia (Detienne \& Vernant, 1988: 48); elemento que, en su variante de tela, emplea Penélope para, metafóricamente, paralizar el avance del tiempo y, así, evitar tomar por esposo a uno de los pretendientes.

Durante el proceso de tejido, las mujeres, con la unión de hilos, crean un nudo que ayudará a dar forma y consistencia a la prenda que se está realizando. Esta operación, desde un punto de vista figurado, aferraría a las féminas al interior del hogar -el gineceo- y, con ello, al esposo, padre o tutor; dificultando que las esposas o las hijas vírgenes se descarriasen del buen camino, pudiendo dañar su reputación y la de su familia. Este espacio femenino, privado y cerrado, se convierte en un lugar de secretos y actividad potencialmente subversiva (Clayton, 2009: 37); estableciéndose un vínculo tan íntimo con las mujeres que, sin la existencia de este ámbito, el continuo tejer y destejer de Penélope no podría llegar a interpretarse como un discurso femenino (Clayton, 2004: 43).

Penélope, más allá de ser una de las mayores hacedoras de productos físicos e intelectuales (Thomas, 1988: 261), sabe convertirse en objeto de simpatía y aprecio: sus engañifas, a diferencia de las de Odiseo, no entrañan miseria o muerte a otros personajes. Ella, mêtis personificada en mortal, está preparada para habitar en un universo masculino sin ser esclavizada, pues engatusa al hombre con un manejo cuidadoso de las virtudes que se les impusieron a las féminas: castidad, fidelidad y modestia (Gualerzi, 2007: 114). Y, mediante la tejeduría, construye una inteligencia (Andò, 2005: 55) que dará origen a una forma de expresión propia de las mujeres griegas: el tejido como voz y palabra femenina. 


\section{Conclusión}

En este breve texto, mediante una revisión bibliográfica y documental, se ha buscado explicitar dos objetivos fundamentales: primero, dar a conocer el papel que la tejeduría tenía en la configuración del rol femenino en la antigua Grecia y segundo, exponer cómo la mujer griega -encarnada en las figuras míticas de Aracne, Filomela y Penélope- se serviría de esta labor para configurar un tipo de lenguaje, exclusivamente femenino, que prevaleciese sobre la imposición de silencio dispuesta por el varón griego.

En los ejemplos presentados se señala cómo Aracne y Filomela, por ser expertas tejedoras, están cualificadas para transmitir un mensaje, un pensamiento o una idea mediante su producción textil. No obstante, de entre todas, Penélope es la única capaz de adoptar este saber práctico y emplearlo, en la misma medida, como ardid y palabra; hecho que alude al lenguaje enigmático utilizado por la Esfinge en sus acertijos.

Que Penélope sea la idónea para ejecutar esa doble función deriva, tanto de la naturaleza de su carácter como de su estatus. A diferencia de Aracne, doncella huérfana de madre, Penélope ha vivido sus primeros años de instrucción bajo la supervisión materna; figura que la ha guiado por intrincado mundo femenino, aleccionándola en todas las tareas, deberes y comportamientos propios de una mujer de "bien". También, por su papel de esposa y madre, Penélope sabe actuar con sutileza, modestia y recato; cualidades que le serán beneficiosas a la hora de engañar a los pretendientes. Por el contrario, Aracne, desconocedora de la correcta actitud de las féminas, solo sabrá actuar de forma irreverente, lo que derivará en el terrible castigo al que es sometida.

Mientras el movimiento de la tejedora arquetipo -Aracne y Filomela- procede por idas y vueltas, el de Penélope resulta de un continuo hacer y deshacer; un trabajo interminable que, simbólicamente, va configurando un nexo de ideas -entrelazamiento de los hilos de la trama y la urdimbre- del cual surgirá el discurso femenino griego, el tejido o diseño resultante.

\section{Bibliografía}

\section{Fuentes clásicas}

AA. VV. (2002). Yambógrafos griegos. Traducción y notas de Emilio Suárez de la Torre. Gredos. Madrid.

ARistófanes. (2007). Lisístrata; Tesmoforiantes; Ranas; Asambleístas; Pluto. Traducción y notas de Luís M. Macía Aparicio. Gredos. Madrid.

Aristóteles (1988). Política. Traducción y notas de Manuela García Valdés. Gredos. Madrid.

ARISTóteles (1999). Retórica. Traducción y notas de Quintín Racionero. Gredos. Madrid. Homero (1993). Odisea. Traducción de José Manuel Pabón. Gredos. Madrid.

Homero (1996). Ilíada. Traducción y notas de Emilio Crespo Güemes. Gredos. Madrid. 
Jenofonte (1993). Recuerdos de Sócrates; Económico; Banquete; Apología de Sócrates. Traducción y notas de Juan Zaragoza. Gredos. Madrid.

Ovidio Nasón, Publio (2012). Metamorfosis. Libros VI-X. Traducción y notas de Jóse Carlos Fernández Corte y Josefa Cantó Llorca. Gredos. Madrid.

Plutarco (1987). Obras Morales y de Costumbres (Moralia) III. Traducción y notas de Mercedes López Salvá y María Antonia Medel. Gredos. Madrid.

Plutarco (2002). Obras Morales y de Costumbres (Moralia) IX. Traducción y notas de Vicente Ramón Palerm y Jorge Bergua Cavero. Gredos. Madrid.

\section{Obras generales}

Andò, VAlERIA (2005). L'ape che tesse. Saperi femminili nella Grecia Antica. Carocci. Roma. ASSAËL, JACQUELINE (2002). Tisser un chant, D’Homer à Euripide. Gaia. Revue interdisciplinaire sur la Grèce ancienne, 6, 145-168.

Blok, Josine (2017). Citizenship in Classical Athens. Cambridge University Press. Cambridge. https://doi.org/10.1017/9781139017916

BLundell, Sue (1995). Women in ancient Greece. Harvard University Press. Cambridge.

BRuit Zaidman, Louise \& SChmitt-PANTEl, PAuline (2002). La religión griega en la polis de época clásica. Akal. Madrid

Clayton, Barbara (2004). A Penelopean Poetics. Reweaving the Feminine in Homer's Odyssey. Lexington Books. Oxford.

Dalton Palomo, Margarita (1996). Mujeres, diosas y musas: tejedoras de la memoria. El colegio de México. México.

Detienne, Marcel, \& Vernant, Jean-Pierre (1988). Las Artimañas de la inteligencia: la "metis" en la Grecia antigua. Taurus. Madrid.

FANTHAM, Elaine [et al.] (1995). Women in the classical world. Oxford University Press. New York.

FERnÁndez Guerrero, Olaya (2012). El hilo de la vida. Diosas tejedoras en la mitología griega. Feminismo/s, 107-125.

FRONTISI-DUCROUX, FRANÇOISE (2006). El hombre-ciervo y la mujer-araña. Figuras griegas de la metamorfosis. Abada Ediciones. Madrid.

Frontisi-Ducroux, Françoise (2009). Ouvrages de dames. Ariane, Hélène, Pénélope. Éditions du Seuil. Paris.

Frontisi-Ducroux, Françoise, \& Vernant, Jean-Pierre (1997). Dans l'œil du mirror. Éditions Odile Jacob. Paris.

GeA IzQuiERdo, Francisco JaviER. (2013). El amor en la Antigüedad. CreateSpace Independent Publishing Platform. Versión digital.

Gera, Deborah (1997). Warrior Women. The anonymous Tractatus de Mulieribus. E. J. Brill. Leiden; New York \& Köln.

GonzÁlez GonzÁlez, Marta (2008). La metis de Procne. Acerca de Esquilo, Suplicantes. Minerva, 21, 57-61. 
Gualerzi, Saverio (2007). Penelope o della tessitura. Trame femminili da Omero a Ovidio. Palomar. Bari.

IRIARTE, ANA (1990). Las redes del enigma: voces femeninas en el pensamiento griego. Taurus. Madrid.

LefKowitz, MARY (1983). Wives and husbands. Greece and Rome, Vol. 30, № 1, 31-47.

LisSARrague, François (2003). Intrusiones en el gineceo. Los misterios del gineceo. Akal. Madrid. 158-198.

LORAUX, Nicole (1989). Maneras trágicas de matar a una mujer. Antonio Machado Libros. Madrid.

Nosch, MARIE LouISE (2014). Voicing the Loom: Women, Weaving, and Plotting. KE-RAME-JA. Studies Presented to Cynthia W. Shelmerdine. INSTAP Press, Prehistory Monographs, vol. 46, pp. 91-101.

OsBorne, Robin (1996). Greece in the making 1200-479 B.C. Routledge History of the Ancient World. London \& New York.

Papadopoulou-Belmehdi, Ioanna (1994). Le Chant de Pénélope. Poétique du tissage féminin dans l'Odyssée. Belin. Paris.

Scheid, John; \& SVEnbro, JeSPER (1996). The craft of Zeus: myths of weaving and fabric. Harvard University Press. Cambridge \& London.

Thomas, Carol (1988). Penelope's worth: looming large in Early Greece. Hermes, 116, 257-264. 